\title{
IDEAL-Cell, a high temperature Innovative Dual mEmbrAne fuel-Cell
}

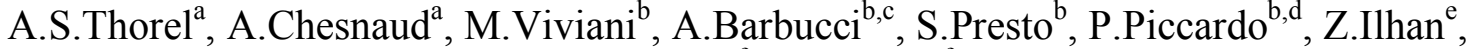 \\ D.Vladikova ${ }^{\mathrm{f}}$, Z.Stoynov $^{\mathrm{f}}$ \\ ${ }^{a}$ Centre des Matériaux, Mines-ParisTech, BP87, Evry Cedex 91003, FRANCE \\ ${ }^{\mathrm{b}}$ Institute for ENergetics and Interphases (IENI-CNR), National Research Council, \\ Genova 16149, ITALY \\ ${ }^{\mathrm{c}}$ Department of Chemical and Process Engineering (DICHeP), University of Genova, \\ Genova 16129, ITALY \\ ${ }^{\mathrm{d}}$ Department of Chemistry and Industrial Chemistry (DCCI), University of Genova, \\ Genova 16146, ITALY \\ ${ }^{\mathrm{e}}$ German Aerospace Center (DLR-ITT) Pfaffenwaldring 38-40, Stuttgart D-70569, \\ GERMANY \\ ${ }^{\mathrm{f}}$ Institute of Electrochemistry and Energy Systems - BAS, 10 Acad. G. Bonchev St., \\ Sofia 1113, BULGARIA
}

IDEAL-Cell is a new concept of a high temperature fuel cell operating in the range $600-700{ }^{\circ} \mathrm{C}$. It is based on the junction between the anode part of a PCFC and the cathode part of a SOFC through a mixed $\mathrm{H}^{+}$and $\mathrm{O}^{2-}$ conducting porous ceramic membrane. This concept, extensively described in the present paper, aims at avoiding all the severe pitfalls connected with the presence of water at the electrodes in both SOFC and PCFC concepts. Spark Plasma Sintering samples were designed specifically for proving the IDEAL-Cell concept. The first electrochemical results obtained at $600{ }^{\circ} \mathrm{C}$ under hydrogen on millimeter thick samples show that IDEAL-Cell behaves like a high temperature fuel cell.

It is estimated that the overall efficiency of this new concept should greatly surpass that of standard SOFCs and PCFCs and that the material constraints, especially in the case of interconnect materials, should significantly decrease.

\section{Introduction}

Conventional solid oxide fuel cells (SOFC) and proton conducting solid oxide fuel cells (PCFC) are promising high temperature fuel cell systems, though at different stages of development. SOFCs are more mature, and prototypes do exist with geometries that derived from two main different designs, tubular and planar. In either case, the SOFCs systems are operating in the range $800-1000{ }^{\circ} \mathrm{C}$, and are most often based on YttriaStabilized Zirconia (YSZ) as the electrolyte material. The anode is usually a Ni-YSZ cermet, whereas the cathode is generally a lanthanum-strontium manganese oxide (LSM). Recent developments have brought about a decrease in SOFCs operating temperatures down to the $600-700{ }^{\circ} \mathrm{C}$ range through the concept of an anode supported or metal supported design, on which a thin layer of electrolyte is deposited, as well as through materials development (SOFC based on Y or Gd-doped cerium oxide, respectively YDC15 and GDC20, and lanthanum-strontium-(iron)-cobalt oxide, LSC(F)). 
The advent of a different mechanism for conduction, PCFCs (proton conducting ceramic based fuel cells) has given rise to a new impetus in the fuel cell field. These systems, based on barium or zirconium cerates perovskite structures, exhibit potential performances at $600{ }^{\circ} \mathrm{C}$ that are equivalent to those of YSZ based SOFCs at higher temperatures. However, a PCFC material that can efficiently ensure the specific conditions required at the cathode, is yet to be developed.

Though potentially very attractive in the long term, even the more mature SOFC systems based on YSZ show an efficiency hardly higher than $40 \%$ for fuel utilization (up to $80 \%$ if the fuel is recirculated), and an electrical efficiency in the range of the $50 \%-$ $60 \%$. This, in addition to the important costs of development and manufacture, significantly slows down their marketing.

Even if some SOFC prototypes have already exhibited several 10,000 hours of stable operation, both SOFC and PCFC technologies still suffer from principle drawbacks, which are directly linked to the unavoidable occurrence of water at the electrodes - at the anode in SOFC and at the cathode in PCFC (figure 1).

SOFC

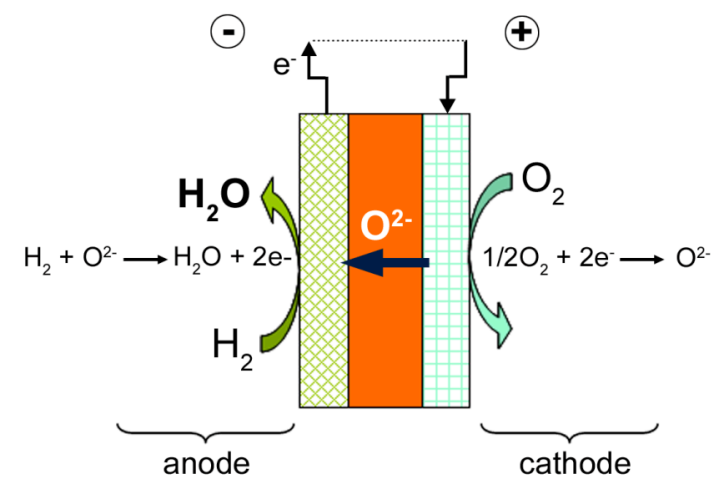

PCFC

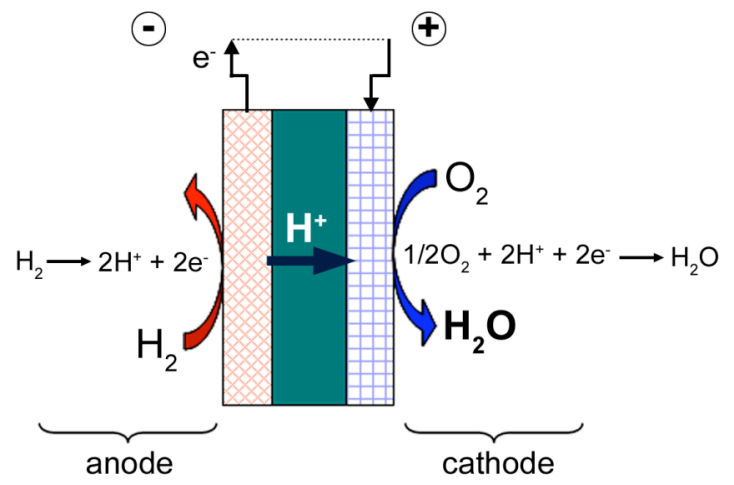

Figure 1. In the a SOFC water appears at the anode, diluting the fuel (left) whereas in a PCFC water appears at the cathode, diluting the oxidizer (right).

The immediate negative consequence for both systems constitutes in an overall loss of efficiency through:

- severe corrosive environment at the cell-interconnect interface (high temperature water and $\mathrm{H}_{2}$ or $\mathrm{O}_{2}$ ) resulting in a need for sophisticated interconnects;

- dilution of fuel or oxidizer;

- reduced catalytic activity at the reaction sites due to the presence of water causing lower performance;

- counter flow of gas to remove the water, which acts against heat management and overall efficiency;

- "open systems" design of electrodes, which allows water evacuation, but does not permit operation under pressure;

- water and gases carrying heat out of the system. 


\section{The IDEAL-Cell concept}

The basic ideas behind the concept

The work described in this paper aims at developing a new innovative and competitive concept for a high temperature fuel cell, operating in the range $600-700{ }^{\circ} \mathrm{C}$, which combines the advantages and eliminates the disadvantages of both oxygen conducting and proton conducting SOFC. It is based on the idea of a more efficient system design, which can be achieved through the complete elimination of water from the electrodes.

It is clear that in existing fuel cell designs water is not present at the SOFC cathode and at the PCFC anode. The idea is then to take advantage using only those components that are free of water in operation. The new design eliminates the SOFC anode and the PCFC cathode, and thus ensures a structure where both hydrogen and oxygen ions should re-combine and electrons should be collected in an external circuit. Thus the IDEAL-Cell concept joins a PCFC anode/PCFC electrolyte part (anode compartment) and an SOFC electrolyte/SOFC cathode part (cathode compartment) through a mixed $\mathrm{H}^{+}$and $\mathrm{O}^{2-}$ conducting porous ceramic membrane made of a composite based on both PCFC and SOFC electrolytes (figure 2).

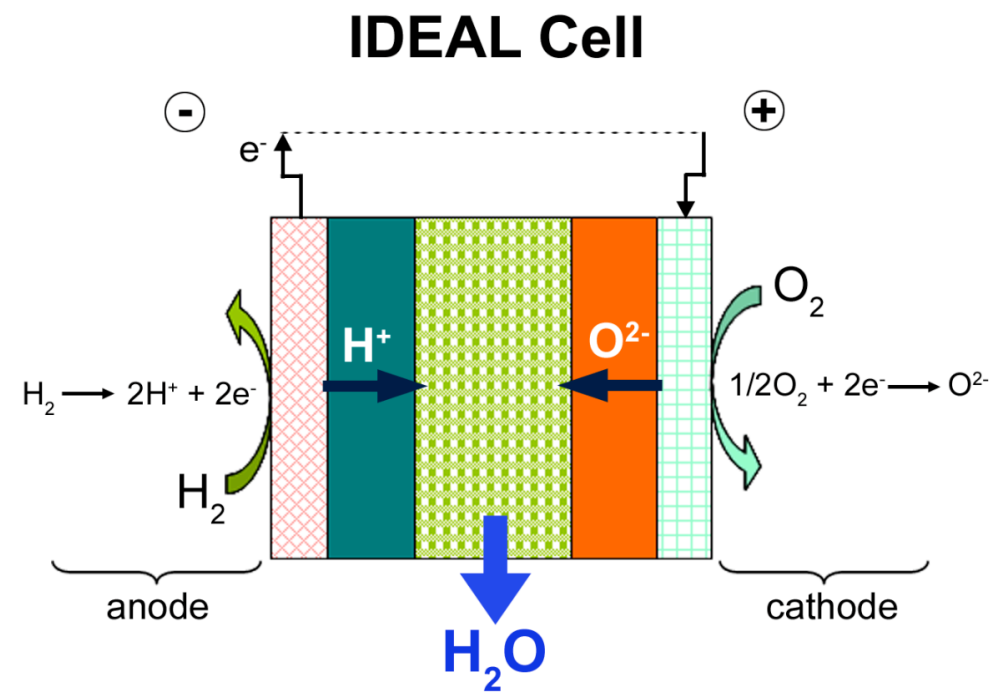

Figure 2. Schematic representation of the IDEAL-Cell concept.

Protons created at the anode progress towards the central membrane where they meet with oxygen ions created at the cathode and form water, which is evacuated through the porous central membrane. Therefore, in this concept, hydrogen, oxygen and water are located in three independent chambers, which allows for the avoidance of all the detrimental consequences discussed above.

The innovative concept, named IDEAL-Cell after the acronym of a 4-year FP7 European project (1), has the potential of considerably enhancing the overall system efficiency (fine-tuning of the electrodes catalytic properties, possibility for applying pressure to both electrode compartments, simpler and more compact stack-design with

${ }^{1}$ See www.ideal-cell.eu 
less sophisticated interconnects, more efficient pre-heating of gases, simplified heat exchange system for co-generation, availability of high quality pure water for vapor reforming...).

\section{Technical aspects}

IDEAL-Cell is in its first stage of development, which focuses on concept validation. In that context, the proof of the concept is based on the use of existing materials, which must be physically and chemically compatible (no reactivity), and which must exhibit a significant conduction at $600{ }^{\circ} \mathrm{C}$. Therefore, the first version of IDEAL-Cell is based on the following sequence of materials:

- $\mathrm{BaCe}_{0.85} \mathrm{Y}_{0.15} \mathrm{O}_{2.925}(\mathrm{BCY} 15)+\mathrm{Ni}$ for the anode;

- $\quad \mathrm{BaCe}_{0.85} \mathrm{Y}_{0.15} \mathrm{O}_{2.925}$ for the hydrogen electrolyte;

- $\mathrm{BaCe}_{0.85} \mathrm{Y}_{0.15} \mathrm{O}_{2.925}+\mathrm{Ce}_{0.85} \mathrm{Y}_{0.15} \mathrm{O}_{1.925}$ (YDC15) for the porous central membrane;

- $\mathrm{Ce}_{0.85} \mathrm{Y}_{0.15} \mathrm{O}_{1.925}$ for the oxygen electrolyte;

- $\mathrm{La}_{0.60} \mathrm{Sr}_{0.40} \mathrm{CoO}_{3-\delta}$ (LSCF40) or $\mathrm{La}_{0.60} \mathrm{Sr}_{0.40} \mathrm{Co}_{0.20} \mathrm{Fe}_{0.80} \mathrm{O}_{3-\delta}$ (LSCF48) for the cathode;

- CROFER 22 APU for the interconnects.

The use of YDC15 instead of the more standard Gadolinium doped Ceria aims to diminish the chemical gradient across the cell, and thus to increase the stability under operation. The amount of acceptor dopant selected for BCY15 corresponds to the maximum conductivity at $600{ }^{\circ} \mathrm{C}(2)$. BCY15 and YDC15 are a priori compatible materials (3) since the latter is a decomposition product of the first one at high temperature (i.e. at the sintering temperature: $1450{ }^{\circ} \mathrm{C}$ ) when $\mathrm{BCY} 15$ is Ba deficient. CROFER 22 APU is used as a first version of the IDEAL-Cell interconnect, but work is under progress to find a less sophisticated material with less Chromium that can operate in a non humid electrode atmosphere.

The key-point of IDEAL-Cell development will be the design and fabrication of the porous central membrane, which has to ensure the recombination of hydrogen and oxygen ions, the formation and evacuation of water. The challenge here will be to obtain a membrane with three percolating phases (BCY15, YDC15 and a porosity network) that will present as little resistance as possible to each mechanism of conduction, and will facilitate the occurrence of the chemical reaction for water formation. Extensive experimental and theoretical work is being done to fabricate and join the different compartments of IDEAL-Cell (4), to understand and model the elementary mechanisms of ion recombination, water formation and evacuation at the central membrane level (5). This will allow for fine-tuning of the design of the central membrane, hence of the IDEAL-Cell.

\section{$\underline{\text { Proof of concept criteria }}$}

Experimental proof of the IDEAL-Cell concept requires that the cell behaves electrochemically like a fuel cell and that water produced from the recombination of ions is present at the central membrane during cell operation. The last point is quite delicate since BCY15 needs water to function; therefore just "additional" water formation should be detected and cross-correlated to other more straightforward criteria to prove the 
concept. It is then inferred that the proof of the IDEAL-Cell concept should be evaluated through 4 criteria:

- (i) a stable OCV under hydrogen and air;

- (ii) a stable polarization curve (V/I);

- (iii) a specific impedance fingerprint for the appearance of water;

- (iv) clear and direct evidence of water in the central membrane.

\section{Experimental}

The first experiments were performed on $3 \mathrm{~mm}$ thick multilayered cells made of a mixed $\mathrm{BaCe}_{0.85} \mathrm{Y}_{0.15} \mathrm{O}_{2.925}+\mathrm{Ce}_{0.85} \mathrm{Y}_{0.15} \mathrm{O}_{1.925}$ porous central membrane sandwiched between dense $\mathrm{BaCe}_{0.85} \mathrm{Y}_{0.15} \mathrm{O}_{2.925}$ and $\mathrm{Ce}_{0.85} \mathrm{Y}_{0.15} \mathrm{O}_{1.925}$ electrolyte layers. Such structures were prepared by Spark Plasma Sintering (SPS) (4). The sintered ceramics, $10 \mathrm{~mm}$ in diameter and $3 \mathrm{~mm}$ thick, were annealed in air at $650{ }^{\circ} \mathrm{C}$ for $10 \mathrm{~h}$ in order to remove graphite from the central membrane and excess oxygen vacancies possibly produced during SPS. Figure 3 shows a lateral view of an SPS pellet after annealing.

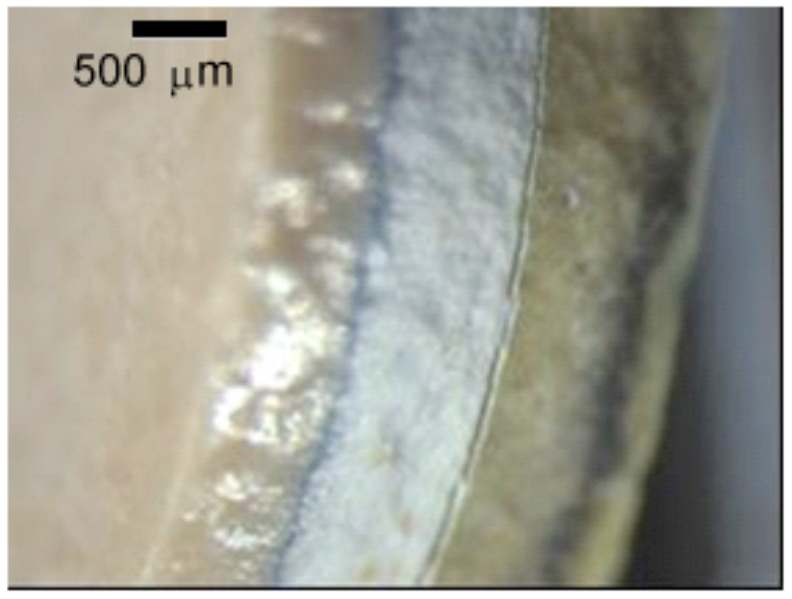

Figure 3. Three-layer sample fabricated by SPS. Left to right: YDC15-CM-BCY15.

Circular Pt electrodes $\left(0.12 \mathrm{~cm}^{2}\right)$ were formed on both sides by brushing a Pt-ink (Metalor) and curing at $1000{ }^{\circ} \mathrm{C}$. The cells were tested in a two-electrode configuration at atmospheric pressure. Oxygen and hydrogen diluted with nitrogen in different ratios were fed to the cathodic and anodic compartments respectively. The anodic gas mixture was bubbled in water at $25{ }^{\circ} \mathrm{C}$ for humidification. The cell was placed on the top of an alumina tube and sealed to ensure a separate gas-tight anodic compartment. Another alumina tube with a dead end was fitted to the previous one to form the cathodic compartment. Pt meshes were placed at both sides of the cell. The alumina tubes together with thermocouples and Pt wires, welded to the Pt meshes, were connected to a metal support (Probostat, NorEcs) along with gas and electric connections..A schematic of the measurement rig assembly is given in figure 4, together with an image of an SPS threelayer sample sealed on the supporting tube of the measurement rig. The alumina part of the cell rig was placed in a tubular furnace (Carbolite). Chronopotential, polarization and impedance measurements were carried out using a potentiostat-impedancemeter (Autolab, Pgstat30). 

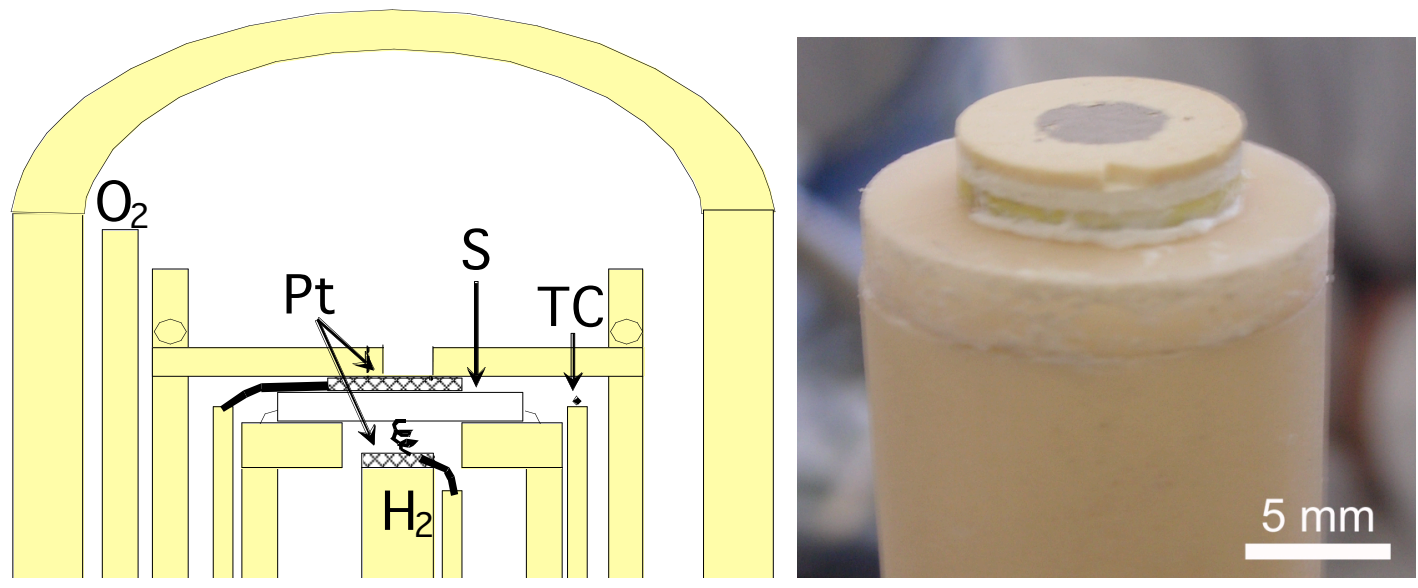

Figure 4. Schematic of the measurement rig (left) and sample sealed on supporting tube (right). $\mathrm{S}=$ sample, $\mathrm{TC}=$ thermocouple, $\mathrm{Pt}=$ platinum mesh, $\mathrm{H}_{2} / \mathrm{O}_{2}=$ supplies.

\section{Results and discussion}

Samples were heated to $900{ }^{\circ} \mathrm{C}$ under $\mathrm{N}_{2}$ in order to cure the ceramic sealing paste supply and "switched-on" by applying wet $\mathrm{H}_{2}$ and dry $\mathrm{O}_{2}$ gases to the anodic and cathodic compartments respectively. The cell voltage under open circuit (OCV) conditions was recorded down to the test temperature $\left(600^{\circ} \mathrm{C}\right)$. Figure 5 represents the $\mathrm{OCV}$ value over an interval of 40 minutes at $600{ }^{\circ} \mathrm{C}$, indicating a stable value close to 1.0 $\mathrm{V}$. The inset shows the switch-on at $900{ }^{\circ} \mathrm{C}$, with quick (less than $1 \mathrm{~min}$ ) stabilization at the equilibrium value $(0.75 \mathrm{~V})$.

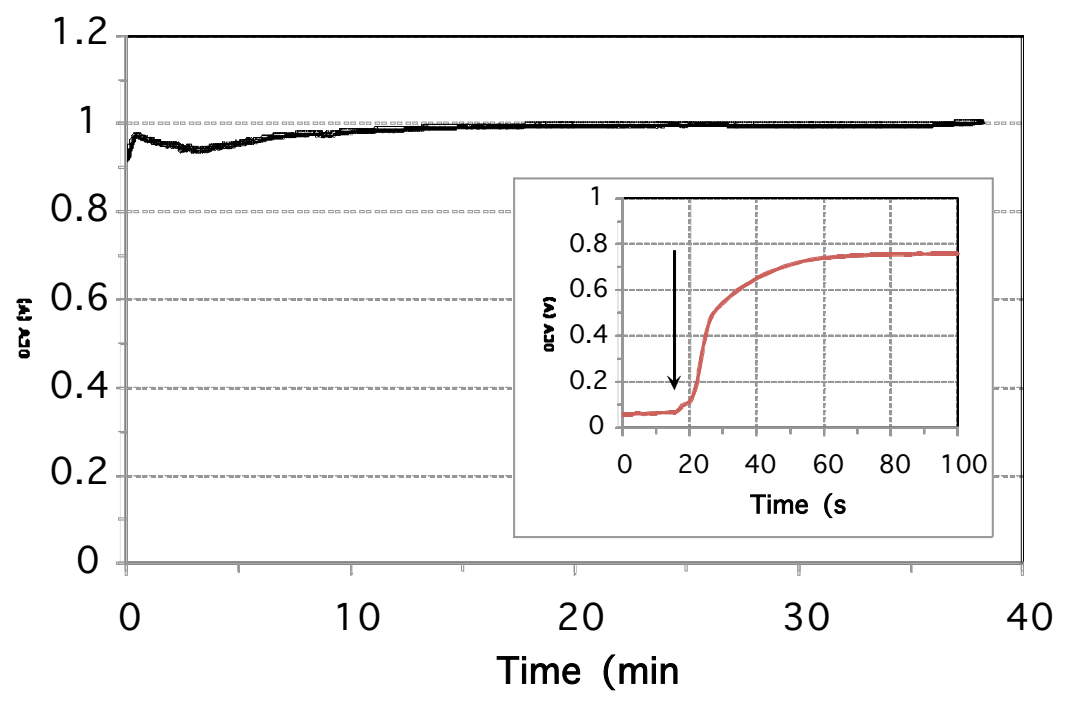

Figure 5. Open circuit potential vs. time at $600{ }^{\circ} \mathrm{C}$ for a three-layer sample. Inset: OCV across the switching from a $\mathrm{N}_{2}-\mathrm{N}_{2}$ to a $\mathrm{H}_{2}-\mathrm{O}_{2}$ supply at $900{ }^{\circ} \mathrm{C}$, indicated by the arrow.

Polarization measurements were carried out in both potentiostatic and galvanostatic modes. One example, collected at $600{ }^{\circ} \mathrm{C}$ under $\mathrm{H}_{2}-\mathrm{O}_{2}$ gases, is given in figure 6 . The response was reproducible and sensitive to partial pressure of the gases, as it is expected from a standard fuel cell. At low current densities the cell behavior is strongly governed by activation mechanisms. The specific power output was relatively low in all cases. 


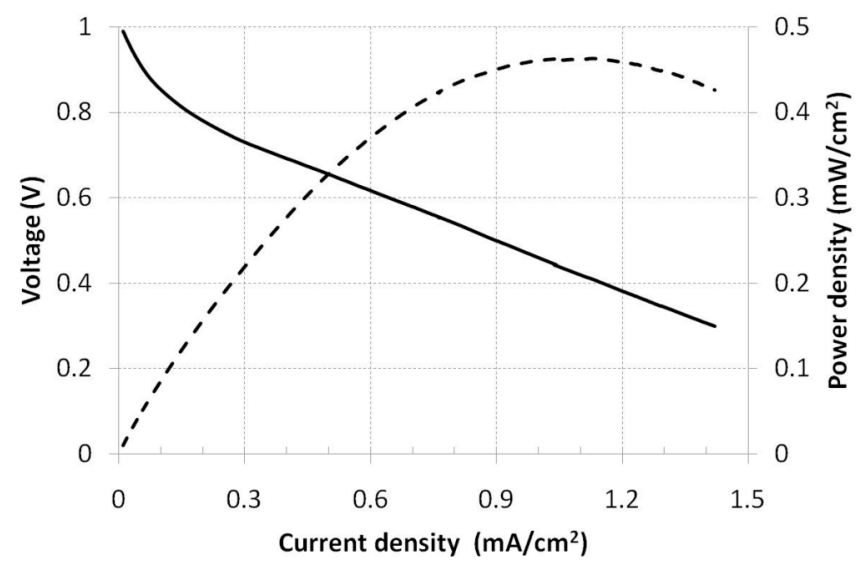

Figure 6. Cell voltage (solid) and power density (dashed) curves vs. current density obtained at $600{ }^{\circ} \mathrm{C}\left(\mathrm{H}_{2}-\mathrm{O}_{2}\right)$.

The low activity of the electrodes used, the very thick dense electrolyte layers and the non-optimized dual membrane negatively affect the cell performance. However, the emphasis during the first stage of this study falls on proving the IDEAL-Cell concept with the simplest cell design and the highest robustness possible. Our second target consists in determining a general frame of realistic experimental parameters, which will serve as a basis for the extensive modeling activities that are in progress on the IDEALCell design (5).

Impedance measurements were carried out at different temperatures, gas concentrations and under polarization. Methodological experiments were performed on cathode and anode half cells obtained by different shaping techniques (4). The observed results correlate well with similar measurements presented in the literature (6). However, they are out of the frame of this work. The present analysis aims at a deeper understanding the impedance behavior of the new cell design in relation to the proof of the water formation. The absolute values of impedance are consistent with the d.c. measurements, i.e. the total resistance of the samples is in the range of $\mathrm{k} \Omega$ at $600{ }^{\circ} \mathrm{C}$.

An interesting feature was observed under large perturbation signal. Figure 7 reports impedance spectra in the complex plane representation collected at $600{ }^{\circ} \mathrm{C}$ with $\mathrm{H}_{2}-\mathrm{O}_{2}$ supply in galvanostatic mode.

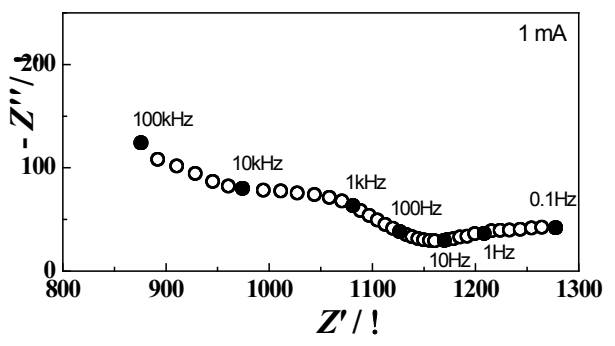

(a)

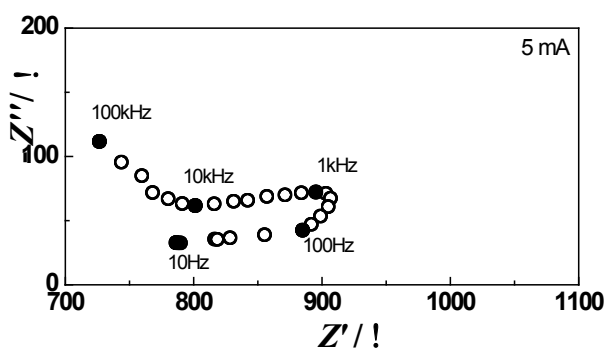

(b) 
Figure 7. Complex plane impedance diagrams of a three-layered sample measured at $\mathrm{OCV}$ at $600^{\circ} \mathrm{C}$ in galvanostatic mode at different perturbation amplitudes.

At lower perturbation signals $(0.5 \mathrm{~mA}$ to $1 \mathrm{~mA})$ the impedance diagrams feature three arcs (Figure $7 \mathrm{a})$. When applying a larger perturbation signal $(5 \mathrm{~mA})$, the impedance diagram shows a "negative" arc with respect to the differential resistance, i.e. decreasing values of the real part of the impedance $\left(Z^{\prime}\right)$ with increasing time of perturbation and quantity of electricity passing through the cell for half period (Figure $7 \mathrm{~b}$ ). Similar phenomenon (smaller negative arcs) has been reported in the literature (7) and observed in our measurements of cathodic and anodic half-cells.

The mathematical explanation of this result is developed on a two-steps reaction model. When the reaction rate coefficient of the second step (last arc in our case) is higher than that of the first (previous) step, the impedance diagram has a "negative" arc (7). From a phenomenological point of view this behavior could be related to the formation and growth of a new phase - in our case that should be the water formation. When the clusters of the new phase are small, i.e. under the critical size, the differential resistance is positive. When the clusters reach the critical size, their further growth becomes a spontaneous process, which is presented in the impedance diagrams with "negative" differential resistance, i.e. they continue to grow with smaller external energy. This explanation follows the classical Gibbs theory for formation and growth of new phases (8). It has been experimentally confirmed in electrochemical investigation of monoatomic (2D) phase formation, in new phase formation studies at the electrodes of classical lead-acid batteries, in corrosion of metals etc... In our experiments the formation and growth of the new phase becomes visible from an impedance point of view at large enough perturbation signals in the low frequency range, since those conditions ensure for half period the necessary quantity of electricity for the formation of a larger number of overcritical clusters of the new (water) phase. Although promising, those first impedance results need more precise methodological experiments to prove the hypothesis for the water clusters formation.

A wide range of possibilities for cell performance improvements can be achieved through the use of a cermet anode, a composite or mixed ionic and electronic conductor cathode, and a thin dense electrolyte. For example, current electrolyte thinness for SOFCs and PCFCs ranges between $20 \mu \mathrm{m}$ to $50 \mu \mathrm{m}$, which is to be compared to the almost $1 \mathrm{~mm}$ thickness of each layer in our proof of concept samples. Thus, for this single thickness parameter and its related ohmic losses, performance could be increased easily by a factor of 50. In addition a detailed modeling study is being performed on an improved dual membrane design, which takes into account the possible mechanisms and kinetics of water recombination, the specific ionic conductivities of electrolytes, and the transport and exhaust of the produced water (5). This numerical analysis will give essential guidelines (volume fraction of each solid phase in the central membrane, size and morphology of pores, thickness of components, grain size...) for the fabrication and design of an optimized dual membrane with reduced cell losses and overpotentials.

Mechanical failure of all cells was observed after testing, which was most likely as a result of residual stresses introduced in the ceramic layers during the sintering process. This can be at least partially avoided through an annealing thermal treatment, at a temperature high enough for species diffusion to take place and to smooth stress 
concentration, and low enough to avoid any thermal degradation and allotropic transformation (i.e. $1000^{\circ} \mathrm{C}$ ).

Overall results demonstrate that in spite of poor performances (figure 5) due to nonoptimized geometry, materials and microstructures, most of the criteria defined for proving the IDEAL-Cell concept were fulfilled: (i) a very stable OCV close to $1 \mathrm{~V}$ typical for the electrochemical potential of water formation from hydrogen and oxygen was recorded (for long duration), indicating that the rig and samples were gas tight; (ii) a stable and reproducible polarization curve of a typical high temperature fuel cell was recorded, exhibiting a sensible behavior to variation of partial pressure of gas supply, as it is observed in standard fuel cell systems; (iii) a complex impedance fingerprint specific for the formation and growth of a new phase was observed at high current perturbation, which could be attributed to the generation of water in the central membrane. The direct evidence of "additional" water in the central membrane compartment was not attempted in this preliminary work. A newly designed cell rig with third compartment connecting the central membrane to a moisture analyzer has been integrated. The very first experimental results which are not presented here is promising.

The novel IDEAL-Cell concept raises many challenges and fundamental questions, some of which emerged through our first experiments (such as the threshold effect seen in the impedance fingerprint of what seems to be the formation of water, and the exact nature of the recombination mechanism occurring at the central membrane). It should be emphasized that before SOFC prototypes emerged in the pre-market segment, as is the case today, many decades were spent on extensive research in electrochemistry, material science, solid state chemistry and chemistry. IDEAL-Cell is only 1 year old, and within this short lifetime a mere abstract concept has become a real fuel cell. However, an enormous amount of work has still to be done to bring IDEAL-Cell to the level of the mature SOFC systems.

\section{Conclusions}

The first tests of the new IDEAL-Cell concept, which is expected to increase significantly the high temperature fuel cells efficiency, have been carried out successfully. They aim at proving the operation of the innovative design which eliminates the water release at the electrodes.

The electrochemical studies performed on a 3-layer sample (dense BCY15 protonic electrolyte/ porous BCY15-YDC15 dual membrane/ dense YDC15 anionic electrolyte with thin porous platinum electrodes) confirm that the system behaves electrochemically as a high temperature fuel cell and can thus be regarded as the first simplified IDEALCell prototype. As a result, a special experimental set up for direct water release monitoring, is being tested. Further improvements, concerning both the cell design and the electrochemical testing procedures are in progress, while modeling constitutes another important aspect of the IDEAL-Cell optimization process. 


\section{Acknowledgments}

Powders were fabricated by Marion Technologies, France. The research leading to these results has received funding from the European Community's Seventh Framework Programme (FP7/2007-2013) under grant agreement $N^{0} 213389$.

\section{References}

1. See www.ideal-cell.eu

2. G. Chiodelli, L. Malavasi, C. Tealdi, S. Barison, M. Battagliarin, L.Doubova, M. Fabrizio, C. Mortalo', R. Gerbasi, Journal of Alloys and Compounds, 470, 477 (2009)

3. G.Caboche, J.-F.Hochepied, P.Piccardo, K.Przybylski, R.Ruckdäschel, M.R.Ardigó, E.Fatome, S.Chevalier, A.Perron, L.Combemale, M.Palard, J.Prazuch, T.Brylewski, Compatibility and reactivity between materials in an Innovative Dual mEmbrAne fueL-Cell (IDEAL-Cell) design, this issue

4. S.Presto, A.Barbucci, M.Viviani, Z.Ilhan, S.A.Ansar, D.Soysal, A.Thorel, J.Abreu, A.Chesnaud, T.Politova, K.Przybylski, J.Prazuch, Z.Zhao, D.Vladikova, Z.Stoynov, IDEAL-Cell, an Innovative Dual mEmbrAne fueL-Cell: fabrication and electrochemical testing of first prototypes, this issue

5. T. Ou, F. Delloro, C. Nicolella, W. G. Bessler, and A.S. Thorel, Mathematical model of mass and charge transport and reaction in the central membrane of the IDEAL-Cell, this issue

6. S.C. Signal and K. Kendall (Eds.), High Temperature Solid Oxide Fuel Cells: Fundamentals, Design and Applications, Elsevier Ltd. 2003

7. C. Gabrielli, Identification of Electrochemical Processes by Frequency Response Analysis, Technical Report No 004, Solartron, Farnborough, Hampshire, England, 1980.

8. J.W. Gibbs, Thermodynamische Studien, Leipzig, 1892, 376 